\title{
CORRESPONDENCE
}

\section{More ground work needed to prepare students for PhDs}

SIR - John Kirkland's review of Toward a Global PhD? by M. Nerad and M. Heggelund (Nature 454, 408; 2008) emphasizes the increasing popularity of doctoral degrees among students around the world. As a graduate students representative, I have noticed a general and worrisome side effect of this trend in the three universities on two continents where I have been based.

It is striking how many early graduate students around the world complain about being unprepared for science itself, despite having passed their undergraduate degrees with ease. For graduate ecologists, for instance, it is crucial that the experimental design and statistics should be carefully thought through before the project is started. However, despite most universities' requiring a basic course in statistics, many graduates struggle to create properly designed experiments.

Ways around this problem could include practical experience on a project-based MSc course as a prerequisite for enrolling for a PhD, stemming the trend to shorten PhD courses and enhancing the quality of supervision.

Ideally, students should be motivated to learn for themselves and should have access to good library facilities so that they can acquire all the information they need before beginning data collection. But some will struggle to make the leap from an initial grasp of theory to the complexities of experimental design and analysis, and will suffer from this for the remainder of their PhD.

This large gap between undergraduate and graduate courses inevitably leads to money being wasted on badly designed projects that will never be published, and the demoralization of graduates who will never go on to become scientists.

Cristina Banks-Leite Departamento de Ecologia, Universidade de São Paulo, 05508-900, Brazil and Division of Biology, Imperial College London, Ascot, Berkshire SL5 7PY, UK e-mail:banks@ib.usp.br

\section{Talking about the creative use of enhancements}

SIR - In his review 'Inside the mind of a marathon runner' (Nature 454, 583-584; 2008), Andy Miah says he approaches the book What I Talk About When I Talk About Running from the perspective of the ethics of biotechnical enhancements. But the striking title of Haruki Murakami's work deserves further comment.

The title echoes that of one of the most important short-story collections in contemporary American literature, taken from one of the stories it contains: Raymond Carver's What We Talk About When We Talk About Love (Knopf, 1981). That story's themes include death, isolation, drinking and different types of love. Murakami's substitution of "running" for "love" speaks for itself, as does the insularity evoked by moving from "we" to "I".

This shift towards isolation is also picked up in Alan Sillitoe's poignant The Loneliness of the Long-Distance Runner (W. H. Allen, 1959): a phrase that has become better known than the powerful short story that evoked it

Carver himself even fits into Miah's theme of biotechnical enhancements. Some say he did his best work while drinking and smoking, which may have helped ease him into his writing in much the same way as Murakami's coating of Vaseline helped him slip into his triathlon wetsuit.

The term 'enhancement' could also be applied to the work of the aggressive editor Gordon Lish, who in many ways shaped Carver's unique voice. It was Lish who coined the reflective 'What We Talk About When We Talk About Love', an improvement over the story's original and less evocative title 'Beginners'.

Whether we are talking about writing, sport or science, some enhancements pay off.

Jennifer Manning American Committee for the Weizmann Institute of Science, 633 Third Avenue, New York, New York 10017, USA e-mail:jennifer@acwis.org

\section{European grants: a different view puts rich countries ahead}

SIR - Another look at the data used by F. Frischknecht in his Correspondence 'Small countries are unexpected winners in ERC grant tables' (Nature 454, 690; 2008) reveals a different story.

Thirty-eight countries are eligible for European Research Council (ERC) grants. Of the 17 that did not receive any grants, 13 had a population size below the median (based on purchasing power parity, using data from the CIA world factbook at https://www.cia.gov/library/ publications/the-world-factbook/ index.html). At a glance, this might suggest that the smaller countries are the losers.

The reason why this is untrue is obvious, but Frischknecht's figures contain a similar error He concludes that small countries were successful, because he omitted the small countries that did not receive any grants.

Of course, larger countries are less likely to have no successful applicants, because they draw from a larger pool of talent. Consequently, Frischknecht's results are automatically biased.

If we look at the full data and use a log-linear model to regress the number of successful applicants against log-transformed population size and gross domestic product (GDP) per person, we find that the population effect (coefficient of 0.9 , standard error 0.11 ) is not distinguishable from $1(P=0.3)$ indicating no evidence of bias towards smaller countries.

The wealth effect is much more important: doubling GDP per head increases the number of grants tenfold (coefficient of 2.3, standard error 0.49). One might conclude that the winners are the rich countries. Again.

Bob O'Hara Department of Mathematics and Statistics, PO Box 68 (Gustaf Hällströmin katu 2b), FIN00014 University of Helsinki, Finland e-mail: bob.ohara@helsinki.fi

\section{European grants: a lifeline in poorly funded countries}

SIR - I was amused to read in Friedrich Frischknecht's Correspondence 'Small countries are unexpected winners in ERC grant tables' (Nature 454, 690; 2008) that Israel is ranked first in grants received, in relation both to population and to gross domestic product. This is shown in his table analysing grant awards from the European Research Council (ERC) for young-investigator research by country. No doubt this ranking will be used for political capital by various interested parties.

Although this success rate must reflect the excellence of our young scientists, I suspect that it also reflects their degree of desperation. In a country with an average local grant size of US\$30,000-40,000 and a finance ministry that is indifferent or actively opposed to funding academic science, an ERC grant is not just a glittering prize, it is one of the few available options for scientific survival. Rather than using Frischknecht's table as a measure of quality, I submit that its primary utility could be in highlighting countries that do not provide adequate local funding for their scientists.

Mike Fainzilber Department of Biological Chemistry, Weizmann Institute of Science, Rehovot 76100, Israel e-mail:mike.fainzilber@weizmann.ac.il 